\title{
Growth, Thermal, FT-Raman and Dielectric studies of Zinc Magnesium Sulphate crystal
}

\author{
V.S. Kumar ${ }^{1 *}$ C. Kayalvizhi ${ }^{2}$ B. Samuel Ebinezer ${ }^{3}$ R.S. Sundararajan ${ }^{3}$ \\ ${ }^{1}$ Department of Physics, Swami Dayananda College of Arts and Science, Manjakkudi, India \\ ${ }^{2}$ Department of Physics, Government Arts College for women(Autonomous), Kumbakonam, India \\ ${ }^{3}$ Department of Physics, Government Arts College(Autonomous), Kumbakonam, India \\ *Corresponding author e-mail: shanmugavsk.2010@gmail.com
}

Available online at: www.isroset.org

Accepted: 29/Jul/2018, Online: 31/Aug/2018

\begin{abstract}
Zinc Magnesium Sulphate single crystal has been grown from an organic solution by slow evaporation method at room temperature. Good quality transparent crystals were harvested within 25 days. FT Raman analysis confirms the vibrational modes of the compound crystal and the presence of expected functional groups. These crystals were subjected to TG-DSC analysis and its thermal stability was determined. Dielectric studies show the dielectric behavior of the title compound crystal.
\end{abstract}

Keywords - MZE - Zinc Magnesium Sulphate ; TGA - Thermo Gravimetric Analysis; DSC -Differential Scanning Calorimetry; FT Raman - Fourier Transform Raman spectrum.

\section{INTRODUCTION}

Present hi-tech epoch massive concentration has been drawn by crystal growth research due to wide operating wavelength range, high mechanical stability, expected surface morphology for some applications ranging from microelectronics, optoelectronics, communication systems, defense sources etc., High efficient photovoltalic devices, its fabrication, traffic purpose illumination devices widely depend on the crystal growth research. This composite crystal zinc sulphate with magnesium sulphate has excellent optical property with good mechanical strength[1-3].

\section{EXPERIMENTAL PROCEDURE}

\section{Crystal growth}

In order to grow title compound crystals, high purity salts $(99.9 \%)$ of zinc sulphate and magnesium sulphate were used. Single crystals of zinc sulphate mixed magnesium sulphate(MZE) were grown at room temperature by solution growth using slow evaporation method, of an organic solution(ethanol) containing zinc sulphate and magnesium sulphate in equal stoichiometric ratio. The temperature of water in the bath was controlled digitally by using microprocessor. Variation in temperature of the bath can be tuned to an accuracy of $\pm 0.1^{\circ} \mathrm{C}$. Transparent good quality crystals of the MZE crystals were harvested in the span of 25 days. The photograph of the crystal is shown in fig.1.

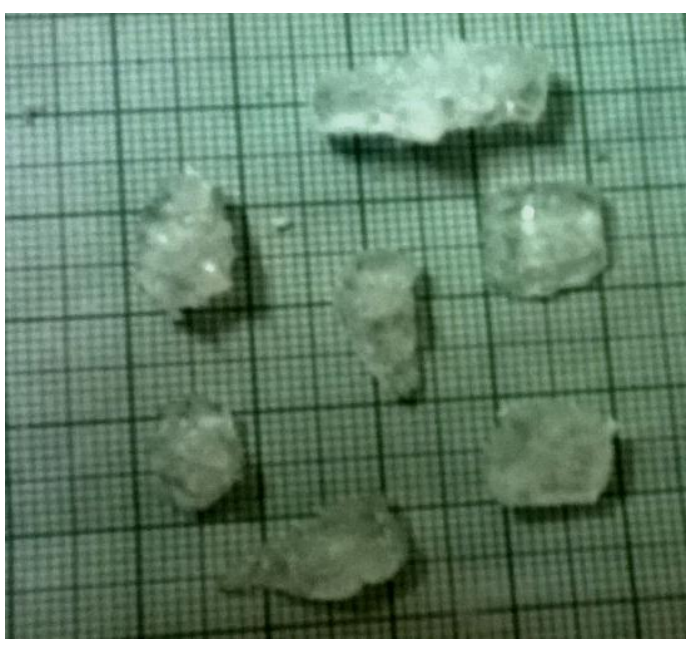

Fig.1 Photograph of MZE crystals

\section{Characterization}

TG-DSC studies of the grown MZE crystals were carried out using instrument NETZSCH STA 449F3. FT-Raman spectrum analysis was recorded in the range of 4000-400 $\mathrm{cm}^{-1}$ using Bruker RFS 27. The dielectric property of the crystal was carried out by digital LCR Z meter THZ816A in the frequency range $50 \mathrm{~Hz}-200 \mathrm{KHz}$.

III. RESULTS AND DISCUSSION 


\section{a. Thermal analysis}

Thermal studies using TGA-DSC give information regarding different stages of decomposition and weight loss of the MZE crystal. TG curve determines the material's thermal stability and its fraction of volatile components by monitoring the weight change. DSC is to maintain the sample and a reference material at same temperature throughout the controlled temperature programme. DSC peaks represent whether it is exothermic or endothermic which is related with the melting point of the compound crystal[4]. The TG curve exhibits different stages of weight loss. First inflection represents the removal of solvent molecules nearly below $100^{\circ} \mathrm{C}$ from the sample, which are organic mixture left in the sample. Upto approximately $10 \%$ of the weight could be lost in this stage above $100^{\circ} \mathrm{C}$. The second stage of TGA curve shows the weight loss about $25.15 \%$ appearing upto $125^{\circ} \mathrm{C}$ indicates the removal of sulphate molecules which are nearly cogent with the melting point of zinc sulphate. Above $150^{\circ} \mathrm{C}$ the weight loss appears upto $750^{\circ} \mathrm{C}$ and it shows the release of magnesium sulphate molecules. TG curve shows the residual mass of nearly $18 \%$ even above $1000^{\circ} \mathrm{C}$. DSC curve shows the peaks at $104.2^{\circ} \mathrm{C}, 130.2^{\circ} \mathrm{C}, 352.5^{\circ} \mathrm{C}$ and $1047.9^{\circ} \mathrm{C}$ which represent different stages of the melting points of the compound crystal. Hence, with the observations it is clear that this compound crystal has good thermal stability and purity.

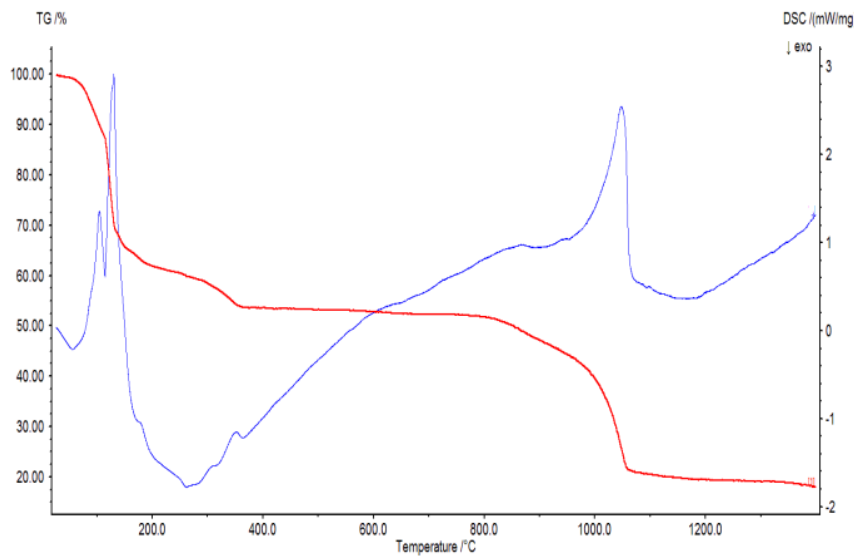

Fig.2 TG-DSC curve of MZE crystal

\section{b. FT-Raman spectral analysis}

The FT-Raman spectrum was recorded for MZE crystals using Bruker RFS 27 instrument in the region 4000-400 cm 1 . The various functional groups present in the material are identified and confirmed in this study. FT Raman spectrum is shown in fig.3.

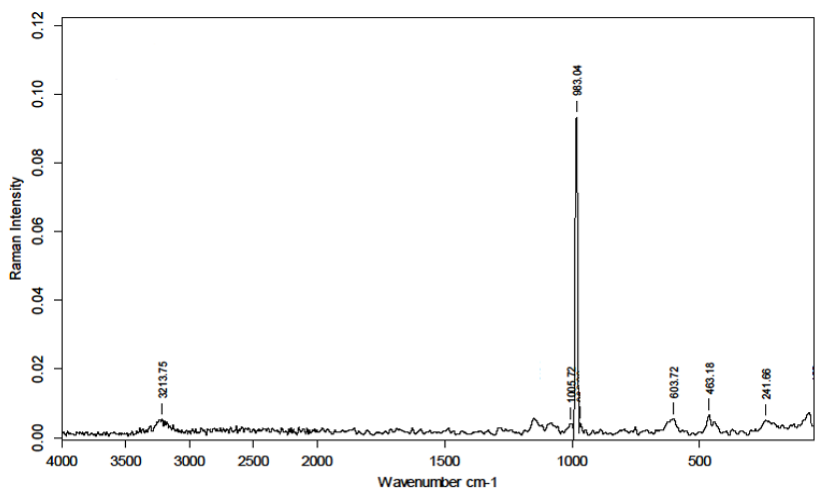

Fig.3 FT-Raman spectrum of MZE crystal

FT-Raman spectrum is recorded in the range as shown in fig.3. Peak $3213.75 \mathrm{~cm}^{-1}$ shows the presence of the alcohol with $\mathrm{OH}$ stretching vibrations. The highest peak of $983.04 \mathrm{~cm}^{-1}$ represents the presence of sulphate very strongly. Peaks at $241.66 \mathrm{~cm}^{-1}$ and $463.18 \mathrm{~cm}^{-1}$ represent the branched alkane presence. Peak $1005 \mathrm{~cm}^{-1}$ is due to the presence of inorganic suplhates when using $\mathrm{KBr}$ discs. Hence, these observed peaks confirm the presence of expected functional groups of the compound crystal [5-9].

\section{c. Dielectric studies}

Dielectric studies are the important characterization that can be used to analyze the electrical properties of a material medium. These are correlated with the electro-optic behavior of the crystals. These are due to the bonding nature of atoms, ions in the materials. The dielectric constant was calculated using the relation, $\varepsilon_{\mathrm{r}}=\mathrm{Cd} / \varepsilon_{0} \mathrm{~A}$ where $\varepsilon_{0}$ is the permittivity of free space, $\mathrm{C}$ the capacitance value, $\mathrm{d}$ the thickness of the sample and $A$ the area of cross section. The dielectric constant of the crystal was measured by using $\varepsilon_{\mathrm{r}}=$ Capacitance of the sample / Capacitance of air. The dielectric property of the crystal was carried out by digital LCR Z meter THZ816A in the frequency range $50 \mathrm{~Hz}-200$ $\mathrm{KHz}$.

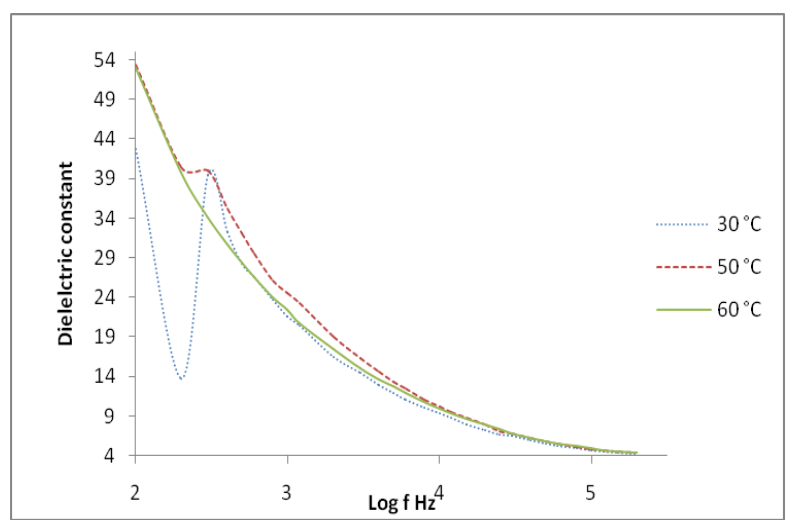

Fig.4 Dielectric constant versus Log $\mathrm{f}$ 


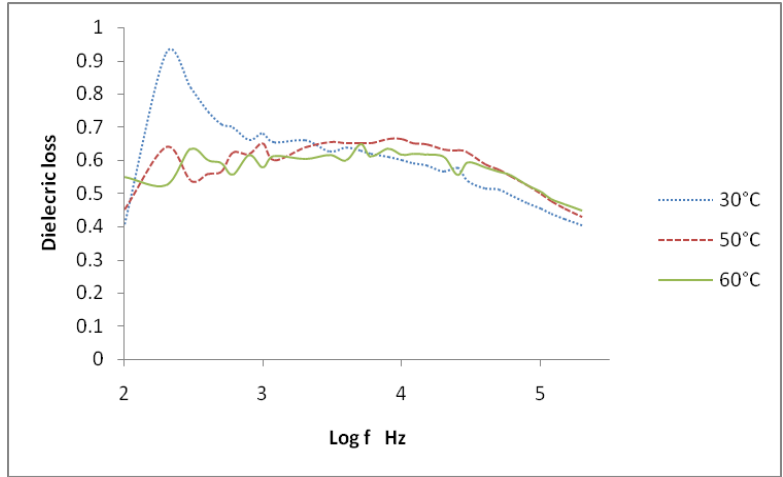

Fig.5 Dielectric loss versus $\log \mathrm{f}$

The dielectric studies were taken under three different temperatures $\left(30^{\circ} \mathrm{C}, \quad 50^{\circ} \mathrm{C}\right.$ and $\left.60^{\circ} \mathrm{C}\right)$. The dielectric constants have high value at low frequency region and then it decreases with gradual increase of frequency for $60^{\circ} \mathrm{C}$ and $50^{\circ} \mathrm{C}$, but it shows a sudden valley decrease at $30^{\circ} \mathrm{C}$ [fig.4]. It may be due to the presence of polarization effect. The dielectric properties were studied as a function of frequency at different temperatures. The reason for the fall on values in dielectric constant predicts that it is due to the space charge, orientation, ionic and electronic polarization effects.

The astounding lower value may be due to the presence of loosely bonded ions inside the crystal. The improvement in dielectric loss at lower frequency originates from space charge polarization[fig.5]. Then the gradual decrease shows the varying relaxation time under intrinsic and extrinsic losses. The intrinsic loss relies upon at the interaction of phonon system with respect to a.c. regulation associated with strength dissipation. Perhaps it is found in pure defect free crystals. On the other extreme level, the extrinsic loss is associated with imperfections in the crystals. The dielectric loss lower value possesses saturation at higher frequency level represents the enhanced optical quality with low density of defects. Hence, this compound crystal may be utilized for microelectronics industry which has low dielectric constant material expectations as an inter layer in the device[10-16].

\section{CONCLUSION}

Zinc magnesium sulphate single crystal has been grown by slow evaporation method at room temperature. Good quality transparent crystals were harvested in a short period within 25 days. FT Raman analysis shows the vibrational modes of the compound crystal and confirms the presence of expected functional groups. The crystals subjected to TG-DSC analysis result good thermal stability. Dielectric studies show the dielectric behavior of the title compound crystal and it reveals that this crystal may be used for microelectronic industrial purposes due its expected output.
It comes to light that these crystals acquire good optical, mechanical, structural, thermal and electrical properties, when doing these research observations. Hence, these crystals may be utilized for opto-electronics and microelectronics purposes.

\section{ACKNOWLEDGEMENTS}

The authors are thankful to SAIF, IIT Chennai and ACIC, St. Joseph's College, Trichy for providing characterization facilities.

\section{REFERENCES}

[1]. Pasupathi.G.,Philominathan.P.,Materialletters,62(2008)43864388.

[2]. Kumar.V.S.,Sundararajan.R.S.,IJSRST,vol.3,issue11(2017)2832.

[3]. Buckley,H.E., Crystal Growth, John Wiley and sons, Newyork, 1951

[4]. Michael E .Brown, Introduction to thermal analysis techniques and applications, Kluwer Academic Publishers, Newyork(2004).

[5]. Ewen Smith, Geoffrey Dent, Modern Raman Spectroscopy,John Wiley and sons Ltd.,(2005).

[6]. Joseph B. Lambert et.al., Introduction to organic spectroscopy, McMillan Pub., Newyork(1987).

[7]. Peter J. Larkin, IR and Raman -principles and spectral interpretation, Elsevier(2011)

[8]. John Coates., Interpretation of IR Spectra, A practical approach,2000, Encyclopedia of analytical chemistry, John Wiley and sons Ltd., pp:1-23.

[9]. George Socrates,2001.Infrared and Raman Characteristics group frequencies tables and charts, $3^{\text {rd }}$ ed.

[10]. Balanagammal.S.,Mahalakshmi.R., Optik.,125(2014)3027-3029.

[11]. Sagadevan suresh, Optik,125(2014)1223-1226.

[12]. Stellamary.S.,ShahilKirupavathy.S.,Gopalakrishan.R.,Optik125( 2014)3837-3843.

[13]. Sagadevan suresh, Optik,125(2014)6746-6750.

[14]. Smyth.C.P.,Dielectric behavior and structure, McGraw Hill, Newyork(1965),pp:132.

[15]. Min-hua Jiang, Qi Fang, Adv.mater.11(1999)1147.

[16]. Hatton.B.T.,Landskron.K.,Hunks.W.J.,Materials chemistry for low -K materials, mater. Today 9(2006),22-31. 